Research Article

\title{
Epidural Labor Analgesia Is Associated with a Decreased Risk of the Edinburgh Postnatal Depression Scale in Trial of Labor after Cesarean: A Multicenter, Prospective Cohort Study
}

\author{
Jing Sun, ${ }^{1}$ Yuci Xiao, ${ }^{1}$ Liwei Zou, ${ }^{1}$ Danyong Liu, ${ }^{1}$ Ting Huang, ${ }^{2}$ Zhao Zheng, ${ }^{1}$ Xuetao Yan, ${ }^{3}$ \\ Aiwu Yuan, ${ }^{4}$ Yuantao Li $\mathbb{D}^{1}{ }^{1}$ and Xiaolei Huang $\mathbb{D}^{1}$ \\ ${ }^{1}$ Department of Anesthesiology, Affiliated Shenzhen Maternity \& Child Healthcare Hospital, Southern Medical University, \\ Shenzhen 518028, China \\ ${ }^{2}$ Department of Obstetrics, Affiliated Shenzhen Maternity \& Child Healthcare Hospital, Southern Medical University, \\ Shenzhen 518028, China \\ ${ }^{3}$ Department of Anesthesiology, Bao'an Maternal and Child Health Hospital, Jinan University, Shenzhen 518106, China \\ ${ }^{4}$ Department of Anesthesiology, Longgang District Maternity \& Child Healthcare Hospital of Shenzhen City, \\ Shenzhen 518172, China
}

Correspondence should be addressed to Yuantao Li; liyuantao6788@yeah.net and Xiaolei Huang; huangmao_sz@163.com

Received 31 July 2019; Accepted 13 December 2019; Published 18 January 2020

Academic Editor: Alberto Raggi

Copyright $(92020$ Jing Sun et al. This is an open access article distributed under the Creative Commons Attribution License, which permits unrestricted use, distribution, and reproduction in any medium, provided the original work is properly cited.

Postpartum depression is a disabling mental disorder commonly seen in parturients under trial of labor after cesarean, which causes serious harm to the parturients. The etiology is unclear. We hypothesized that epidural labor analgesia can reduce the incidence rate of postpartum depression. Enrolled multiparas were divided into the epidural labor analgesia group $(n=263)$ or nonanalgesia group $(n=160)$ according to their own request. Edinburgh Postnatal Depression Scale was used to assess their mental status at 48 hours and 42 days after delivery. Relative perinatal variables were collected and further analyzed using univariate analysis and multivariate logistic regression analysis to assess the relation of epidural analgesia with the occurrence of postpartum depression under trial of labor after cesarean. The Edinburgh Postnatal Depression Scale score 48 hours $\geq 10$ in the no epidural analgesia group was $26.42 \%$ while the epidural analgesia group was $8.49 \%$ (OR, $0.209 ; 95 \%$ CI, $0.096-0.429 ; P<0.001$ ). The Edinburgh Postnatal Depression Scale score 42 day $\geq 10$ in the no epidural analgesia group was $25.16 \%$ while the epidural analgesia group was $6.59 \%(\mathrm{OR}, 0.235 ; 95 \% \mathrm{CI}, 0.113-0.469 ; P<0.001)$. The incidence of postpartum depression was significantly lower in the epidural labor analgesia group at 48 hours and 42 days. There was also a significant relation between the Edinburgh Postnatal Depression Scale scores at 48 hours and 42 days after delivery. Epidural analgesia, discomfort within 42 days, and selfrating anxiety scale are independent predictors of postpartum depression for trial of labor after cesarean in 42 days. Epidural labor analgesia is associated with a decreased risk of postpartum depression. Further study with a large sample size and more centers is needed to evaluate the impact of epidural analgesia on the occurrence of postpartum depression. Chinese Clinical Trial Register, ChiCTR-ONC-17010654.

\section{Introduction}

Postpartum depression (PPD) is a disabling mental disorder usually occurring within 12 months after maternal production, which causes serious harm to both the mothers and families [1]. PPD may cause not only depression, insomnia or lethargy, significant weight loss or increase in weight, psychomotor disturbance or developmental delay, feeling of no value and excessive guilt, decreased self-esteem, and difficulty concentrating but also in extreme cases, self-harm, suicide, or infanticide [2-4]. In addition, it may lead to some childhood and adolescent developmental and behavioral 
problems to the children $[5,6]$. Studies have shown that the incidence of PPD among parturients is about $15 \%$ to $30 \%$ in China, and it receives increasing attention with the implementation of universal two child policy in China [7]. It is reported that many women of childbearing age opt to have a second or third child, 32.7-50\% of which underwent cesarean sections when giving birth the first child [8-11]. Following a cesarean section, the alternative modes for subsequent labor include repeated cesarean section (RCS) and the trial of labor after cesarean (TOLAC). Recent data show that TOLAC is the more effective delivery method because it costs considerably less expense than RCS while also receives better results in reducing the risk of postpartum hemorrhage (PPH) and pelvic adhesions [12]. However, although parturients get better treatment insurance with TOLAC and have experience of giving birth, they are equally prone to anxiety, fear, and tension, even more serious than the first time which is related to their large expectation of the sex and health of the fetus because of the unique culture of preference of boys to girls in China [13]. These factors are prone to PPD and cause harm to parturients. But, the etiology of PPD is complex of which the main risk factors include a history of psychiatric illnesses, mood instability during pregnancy, marital disharmony, poor social support, and stressful life events. Specifically to parturients, the intensity of labor pain was also a factor related to mood disorder in the early postpartum period [14]. The study of Eisenach et al. also confirmed that the severity of acute postpartum pain predicted the occurrence of PPD [15]. Ding Ting et al. reported 4 months after delivery, there was a lower incidence rate of PPD in parturients who received epidural and paracervical blockade during vaginal delivery [16]. In contrast, another study examining PPD rates among 1326 women did not demonstrate a difference between women with intrapartum epidural and those without [17]. Besides the conflicting results in the literature, the subjects of previous studies on PPD are almost aiming at nulliparous women rather than pluripara; therefore, further study is warranted.

We speculated that epidural labor analgesia could decrease the incidence of PPD in TOLAC, especially the vaginal birth after cesarean (VBAC). This study was to investigate correlation of epidural labor analgesia in TOLAC with a decreased risk of PPD.

\section{Materials and Methods}

2.1. Ethics and Informed Consent. The study, which complied with the Helsinki Declaration and relevant Chinese clinical trial research regulations, was approved by the Ethics Committee of Affiliated Shenzhen Maternity \& Child Healthcare Hospital, Southern Medical University, Bao'an Maternal and Child Health Hospital, Jinan University, and Longgang District Maternity \& Child Healthcare Hospital of Shenzhen city. Written informed consent was obtained from all participants. This study was registered in the Chinese Clinical Trial Register (registration number: ChiCTR-ONC17010654), which participated in the World Health Organization International Clinical Trials Registry Platform.
2.2. Study Design and Patient Recruitment. This multicenter prospective, observational cohort design was conducted in three tertiary hospitals in Shenzhen, China, including Affiliated Shenzhen Maternity \& Child Healthcare Hospital, Southern Medical University, Bao'an Maternal and Child Health Hospital, Jinan University, and Longgang District Maternity \& Child Healthcare Hospital of Shenzhen city between February 2017 and February 2018. Inclusion criteria were as follows: multiparas with singleton fetus in the vertex presentation at $\geq 35$ weeks, no systemic analgesics were used currently, and eligible for TOLAC after being assessed by an obstetrician. Parturients with the presence of epidural labor analgesia contraindications were excluded from the study. On admission to Labor Analgesia Consultation Clinic during 34-35 weeks of prenatal, all eligible parturients were informed about the study and signed the consent. According to ACOG Practice Bulletin, [18] labor analgesia could be performed as long as regular uterine contractions began and the parturient required analgesia, so in this study, each parturient made a decision by herself to have epidural labor analgesia or no pain relief at all and then were divided into two groups accordingly: epidural analgesia group, i.e., experiment group $(n=263)$; no epidural analgesia group, i.e., control group $(n=160)$. Other forms of analgesia were not available during labor.

\subsection{General Data Collection}

Baseline Data. Specific information was collected (Table 1). The mental status of parturients was assessed using the Zung Self-Rating Anxiety Scale (SAS) and Social Support Rating Scale (SSRS). SAS was used to evaluate the anxiety and SSRS was used to assess maternal social support, and final scores were calculated and are presented in Table 1. Perinatal data of parturients were recorded (Table 2). Neonatal information including gender, birth weight, and Apgar score at 1 and 5 minutes after delivery was recorded. Apgar score is a standard assessment method for checking the physical condition of a child immediately after birth. A score of 10, 7 or less, and below 4, respectively, indicate normal newborns, mild asphyxia, and severe asphyxia [19].

2.4. Epidural Labor Analgesia. All parturients undergoing TOLAC were observed in the delivery room and underwent continuous electronic fetal monitoring. Vital signs including blood type, electrocardiogram (EEG), hemoglobin (HGB), completing count, and coagulation function were monitored and further assessed whether the parturients were suitable for TOLAC which together with mode of delivery induction of labor or oxytocin and mode of delivery were decided by board certified obstetricians.

For the epidural analgesia group, epidural labor analgesia was administered entering the labor process in the delivery room after cervix examination and contraindications exclusion. Parturients received a standard protocol for labor epidural analgesia. After entering the delivery room, the peripheral venous access of parturients who were experiment group was opened, the lateral recumbent position 
TABle 1: Baseline maternal demographic and obstetric characteristics of parturients who completed the study.

\begin{tabular}{|c|c|c|c|c|c|c|}
\hline \multirow{2}{*}{ Characteristic } & \multicolumn{2}{|r|}{ TOLAC (CTRL) } & \multicolumn{2}{|r|}{ TOLAC (EXP) } & \multirow{2}{*}{$\begin{array}{l}\text { Statistical } \\
\text { value }\end{array}$} & \multirow{2}{*}{$P$ value } \\
\hline & $N($ all $)$ & $n(\%)$ or mean $\pm \mathrm{SD}$ & $N($ all $)$ & $n(\%)$ or mean $\pm \mathrm{SD}$ & & \\
\hline Mode of delivery & 160 & & 263 & & & $<0.001$ \\
\hline Normal delivery & & $111(69.38 \%)$ & & $225(85.55 \%)$ & & \\
\hline Cesarean & & $49(30.63 \%)$ & & $38(14.45 \%)$ & & \\
\hline Hospital name & 160 & & 263 & & 41.021 & $<0.001$ \\
\hline $\mathrm{MCH}$ & & $131(81.88 \%)$ & & $179(68.06 \%)$ & & \\
\hline $\mathrm{BA}$ & & $1(0.62 \%)$ & & $59(22.43 \%)$ & & \\
\hline LG & & $28(17.50 \%)$ & & $25(9.51 \%)$ & & \\
\hline \multicolumn{7}{|l|}{ General information } \\
\hline Age (year) & 160 & $32 \pm 4$ & 262 & $32 \pm 4$ & 21481.5 & 0.667 \\
\hline Gestational age (day) & 158 & $272 \pm 14$ & 260 & $274 \pm 10$ & 18846.5 & 0.157 \\
\hline BMI $\left(\mathrm{kg} / \mathrm{m}^{2}\right)$ & 158 & $26.45 \pm 2.93$ & 259 & $26.59 \pm 3.08$ & 19040.5 & 0.234 \\
\hline Maternal education $>12 \mathrm{y}$ & 116 & $116(72.96 \%)$ & 193 & $193(74.23 \%)$ & & 0.819 \\
\hline Husband education $>12 \mathrm{y}$ & 118 & $118(74.21 \%)$ & 207 & $207(79.62 \%)$ & & 0.228 \\
\hline Housewives & 159 & $13(8.18 \%)$ & 259 & $21(8.11 \%)$ & & 1 \\
\hline Family income $(¥ / \mathrm{mo})^{*}$ & 146 & & 249 & & 0.696 & 0.706 \\
\hline$\leq 10,000$ & & $21(14.38 \%)$ & & $29(11.65 \%)$ & & \\
\hline $10,001-20,000$ & & $53(36.30 \%)$ & & $90(36.14 \%)$ & & \\
\hline$>20,000$ & & $72(49.32 \%)$ & & $130(52.21 \%)$ & & \\
\hline \multicolumn{7}{|l|}{ History of pregnancy and childbirth } \\
\hline Gravidity & & & & & 2.264 & $0.322^{\$}$ \\
\hline 2 & 70 & $70(44.59 \%)$ & 98 & $98(37.69 \%)$ & & \\
\hline 3 & 62 & $62(39.49 \%)$ & 121 & $121(46.54 \%)$ & & \\
\hline$>3$ & 25 & $25(15.92 \%)$ & 41 & $41(15.77 \%)$ & & \\
\hline History of depression and trauma & 158 & $0(0.00 \%)$ & 262 & $4(1.53 \%)$ & & 0.302 \\
\hline Impact of childbirth on work or re-employment & 158 & $10(6.33 \%)$ & 260 & $14(5.38 \%)$ & & 0.672 \\
\hline Maternity leave time & 157 & & 258 & & & 0.031 \\
\hline No & & $1(0.64 \%)$ & & $6(2.33 \%)$ & & \\
\hline Legal time & & $93(59.24 \%)$ & & $178(68.99 \%)$ & & \\
\hline Full-time & & $63(40.13 \%)$ & & $74(28.68 \%)$ & & \\
\hline Anxiety and depression during pregnancy & 158 & $66(41.77 \%)$ & 262 & $87(33.21 \%)$ & & 0.094 \\
\hline Cigarettes, alcohol, long-term medication & 158 & $2(1.27 \%)$ & 261 & $1(0.38 \%)$ & & 0.56 \\
\hline Whether the husband is satisfied with the baby's sex & 158 & $144(91.14 \%)$ & 260 & $236(90.77 \%)$ & & 1 \\
\hline \multicolumn{7}{|l|}{ Caring health knowledge during pregnancy } \\
\hline (1) Routine obstetric examination & 158 & $151(95.57 \%)$ & 261 & $251(96.17 \%)$ & & 0.801 \\
\hline $\begin{array}{l}\text { (2) Attendance at childbirth classes during } \\
\text { pregnancy }\end{array}$ & 158 & $53(33.54 \%)$ & 261 & $121(46.36 \%)$ & & 0.011 \\
\hline $\begin{array}{l}\text { (3) Learn about parenting through cell phones or } \\
\text { books }\end{array}$ & 158 & $132(83.54 \%)$ & 261 & $224(85.82 \%)$ & & 0.573 \\
\hline Unplanned pregnancy & 158 & $62(39.24 \%)$ & 262 & $90(34.35 \%)$ & & 0.346 \\
\hline $\begin{array}{l}\text { Whether the maternal is the only child in one's } \\
\text { family }\end{array}$ & 158 & $17(10.76 \%)$ & 260 & $36(13.85 \%)$ & & 0.449 \\
\hline Changes in marital relationship during pregnancy & 157 & $2(1.27 \%)$ & 260 & $1(0.38 \%)$ & & 0.559 \\
\hline SAS & 156 & $32.88 \pm 6.20$ & 261 & $31.14 \pm 5.89$ & 23757 & 0.004 \\
\hline SSRS & 156 & $45.74 \pm 7.27$ & 261 & $46.27 \pm 5.82$ & 19937.5 & 0.723 \\
\hline MMSE & 156 & $28.15 \pm 1.13$ & 261 & $28.10 \pm 1.06$ & 21158.5 & 0.483 \\
\hline \multicolumn{7}{|l|}{ Prepartum Laboratory test } \\
\hline HGB (g/L:115-150) & 159 & $119.28 \pm 15.05$ & 259 & $116.68 \pm 11.17$ & 22643 & 0.087 \\
\hline PLT (125-350) & 159 & $209.47 \pm 55.51$ & 260 & $210.03 \pm 53.70$ & 20399.5 & 0.822 \\
\hline
\end{tabular}

BMI: body mass index; SAS: Self-Rating Anxiety Scale; SSRS: Social Support Rating Scale; MMSE: mini-mental state examination; HGB: hemoglobin; PLT:

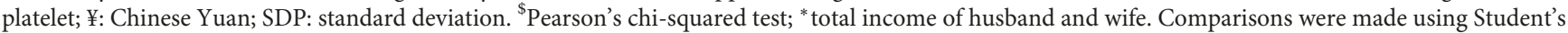
$t$-test or Wilcoxon rank sum test for nonnormally distributed variables. Comparisons were made using Pearson's chi-squared test and Fisher's exact test for proportions.

was taken, and epidural puncture (AS-E epidural catheterization kits) was performed through L2-3 or L3-4 intervals, and the epidural catheter was inserted at a depth of
$3-4 \mathrm{~cm}$. First, the test dose of $3 \mathrm{ml}$ of $1: 200,000$ epinephrine $+1.5 \%$ lidocaine was injected and observed for 3-5 min to exclude the catheter into a body vessel or 
TABLE 2: Perinatal variables of parturients who completed the study for TOLAC.

\begin{tabular}{|c|c|c|c|c|c|c|}
\hline \multirow{2}{*}{ Variable } & \multicolumn{2}{|c|}{ TOLAC (CTRL) } & \multicolumn{2}{|r|}{ TOLAC (EXP) } & \multirow{2}{*}{ Statistical value } & \multirow{2}{*}{$P$ value } \\
\hline & $N($ all $)$ & $N(\%)$ or mean $\pm \mathrm{SD}$ & $N($ all $)$ & $N(\%)$ or mean $\pm \mathrm{SD}$ & & \\
\hline Mode of delivery & 160 & & 263 & & & $<0.001$ \\
\hline VBAC & & $111(69.38 \%)$ & & $225(85.55 \%)$ & & \\
\hline Cesarean & & $49(30.63 \%)$ & & $38(14.45 \%)$ & & \\
\hline Instrumental delivery in VBAC & 27 & & 43 & & & 1 \\
\hline Vacuum extraction & & $15(13.51 \%)$ & & $23(10.22 \%)$ & & \\
\hline Forceps & & $12(10.81 \%)$ & & $20(8.89 \%)$ & & \\
\hline Episiotomy & 149 & $42(28.19 \%)$ & 256 & $111(43.36 \%)$ & & 0.003 \\
\hline Perineum/Cervical laceration & 149 & $70(46.98 \%)$ & 255 & $106(41.57 \%)$ & & 0.3 \\
\hline Uterine rupture & 160 & $0(0 \%)$ & 263 & $0(0 \%)$ & & 1 \\
\hline Estimated blood loss after delivery $(\mathrm{mL})$ & 154 & & 260 & & & 1 \\
\hline$\leq 500$ & & $151(98.05 \%)$ & & $255(98.08 \%)$ & & \\
\hline$>500$ & & $3(1.95 \%)$ & & $5(1.92 \%)$ & & \\
\hline \multicolumn{7}{|l|}{ Labor duration in VBAC } \\
\hline The first labor duration (min) & 108 & $334.14 \pm 225.94$ & 221 & $526.93 \pm 266.85$ & 6050.5 & $<0.001$ \\
\hline The second labor duration (min) & 102 & $28.09 \pm 31.62$ & 217 & $46.14 \pm 32.64$ & 5836 & $<0.001$ \\
\hline The third labor duration (min) & 108 & $8.62 \pm 3.87$ & 222 & $9.43 \pm 5.03$ & 11211.5 & 0.294 \\
\hline Initiating lactation period (hours) & 157 & $11 \pm 13$ & 262 & $7 \pm 12$ & 24276.5 & 0.002 \\
\hline \multicolumn{7}{|l|}{ VAS pain at epidural $(\mathrm{cm})$} \\
\hline T0: time 0 & 99 & $6.34 \pm 2.16$ & 219 & $8.20 \pm 1.19$ & 5191.5 & $<0.001$ \\
\hline T1: PCEA after $30 \mathrm{~min}$ & 100 & $7.00 \pm 2.16$ & 217 & $0.94 \pm 1.61$ & 21103 & $<0.001$ \\
\hline T2: cervical: $6 \mathrm{~cm}$ & 100 & $7.67 \pm 2.33$ & 211 & $1.09 \pm 1.71$ & 20404.5 & $<0.001$ \\
\hline T3: cervical: $10 \mathrm{~cm}$ & 99 & $8.64 \pm 2.13$ & 210 & $1.78 \pm 2.00$ & 20213 & $<0.001$ \\
\hline T4: immediate delivery of the fetus & 97 & $1.65 \pm 2.44$ & 209 & $1.88 \pm 1.60$ & 8062 & 0.002 \\
\hline Feeding patterns within 48 hours & 158 & & 233 & & & 0.361 \\
\hline Breast & & $152(96.20 \%)$ & & $218(93.56 \%)$ & & \\
\hline Milk & & $6(3.80 \%)$ & & $15(6.44 \%)$ & & \\
\hline Feeding amounts within 48 hours & 147 & & 230 & & & 0.491 \\
\hline Normal & & $137(93.20 \%)$ & & $219(95.22 \%)$ & & \\
\hline Discomfort within 42 days & 159 & $33(20.75 \%)$ & 256 & $28(10.94 \%)$ & & 0.007 \\
\hline EPDS score 48 hours & & & & & & $<0.001$ \\
\hline$<10$ & 117 & $117(73.58 \%)$ & 237 & $237(91.51 \%)$ & & \\
\hline$\geq 10$ & 42 & $42(26.42 \%)$ & 22 & $22(8.49 \%)$ & & \\
\hline EPDS score 42 days & & & & & & $<0.001$ \\
\hline$<10$ & 119 & $119(74.84 \%)$ & 241 & $241(93.41 \%)$ & & \\
\hline$\geq 10$ & 40 & $40(25.16 \%)$ & 17 & $17(6.59 \%)$ & & \\
\hline
\end{tabular}

Comparisons were made using Student's $t$-test or Wilcoxon rank sum test for nonnormally distributed variables. Comparisons were made using Pearson's chi-squared test and Fisher's exact test for proportions.

subarachnoid space, and then the drug with $10 \mathrm{ml}$ of $0.1 \%$ ropivacaine mixed solution was administered by the epidural catheter once. After observing for 30 minutes, if there were no obvious adverse reactions such as hypotension, nausea, and vomiting, an analgesic pump could be connected. The analgesic pump capacity was $130 \mathrm{ml}$, and the drug was $0.08 \%$ ropivacaine $+0.4 \mathrm{ug} / \mathrm{ml}$ sufentanil. The ZZB-I pulse type analgesic pump was used, and the parameter setting was as follows: the pulse frequency was one pulse per hour, the dose was $10 \mathrm{ml}$, the injection rate was $400 \mathrm{ml} / \mathrm{h}$, the PCA (patient-controlled analgesia) dose was $8 \mathrm{ml}$, and the locking time was $30 \mathrm{~min}$. Epidural labor analgesia was used until the baby was delivered. It was performed by a certificated anesthesiologist, and anesthetic volume was adjusted until the visual analog scale (VAS) pain score was under 4 . If the parturient could not tolerate the pain or the VAS pain score was higher than 5 during labor, she could require rescue analgesia therapy. Rescue analgesia was with $8 \mathrm{ml}$ of $0.67 \%$ lidocaine. Blood pressure is measured every $5 \mathrm{~min}$ during the first $20 \mathrm{~min}$ and hourly during the continuous patient-controlled analgesia usage. VAS pain scores were recorded 30 minutes after the epidural loading dose. The specific approach of VAS was drawing a $10 \mathrm{~cm}$ horizontal line on the paper. One end of the horizontal line was "no discomfort" in Chinese, the other end was "worst discomfort imaginable" in Chinese, and the middle part indicated different degrees of pain. We let the patient draw a mark on the horizontal line according to the feeling of self, indicating the degree of pain [20]. Anesthesiologists and anesthesia nurses of the three hospitals, who participated in this study, were staying in the delivery room 24 hours a day and trying their best to provide a "full" and "complete" truly painless delivery to every woman who received labor analgesia. For the control group, no analgesics were 
administered and VAS pain scores were recorded during the delivery.

2.5. Postpartum Assessment. The level of depression was assessed at 48 hours and 42 days after delivery using the Edinburgh Postnatal Depression Scale (EPDS) [21, 22]. In this study, PPD was defined as an EPDS score of 10 or higher at 42 days after delivery. Primary outcome was EPDS at 48 hours and 42 days after delivery. The parturients were asked to complete the EPDS 48 hours after delivery and received a call and family visit in 42 days later as a part of a larger follow-up study. All the above questionnaires were completed by parturients themselves, without discussing answers with their families. In the meanwhile, VAS was recorded as an indicator of the level of discomfort within 42 days after delivery. The VAS pain score measurement during labor, the postpartum assessments, and other data collection were performed by five unified training investigators who were not blinded to the type of analgesia but did not participate in the patient care.

2.6. Sample Size Calculation and Statistical Analysis. In previous years, the three hospitals had a labor analgesia rate of about 50 percent; we assumed that the number of patients in each group was equal. PPD was treated as a binary outcome. According to the published literature, we assumed that the incidence of PPD would be $25 \%$ in the nonmedicated parturients and $10 \%$ in the parturients who received analgesia [23-25]. The calculated sample size that would provide $80 \%$ power to see this difference based on a 2 tailed significance level of 0.05 is about 200 patients. Considering the rate of loss of follow-up, the sample was amplified by $10 \%$, and the final minimal sample size was 287 patients. The sample size calculation was performed by using 2 independent proportions' power analysis on PASS 2008 (Kaysville, UT).

Continuous variables are presented as mean \pm standard deviation (SD) or median (interquartile range). Data were compared with the use of $t$-test or Wilcoxon rank sum test. Categorical variables are presented as number of patients (percentage). Data were analyzed with the use of $\chi 2$ test or Fisher's exact test. The association between the use of epidural labor analgesia and the occurrence of PPD was assessed with univariate logistic regression and multivariate logistic regression analysis. Propensity score matching (PSM) was used in this study to validate the results of logistic regression that reduce the potential selection bias. Two-sided $P<0.05$ was regarded as significant. All data were entered and analyzed in R (version 3.5.0).

\section{Results}

3.1. Baseline Maternal Demographic. A total of 515 pregnant women who opted TOLAC were screened for eligibility, and 55 women were excluded based on criteria (Figure 1). 17 of enrolled parturients did not complete the whole study. In the end, 423 in total were included in the analysis, among which 263 were given epidural analgesia while 160 were not. 225 cases in the epidural analgesia group underwent VBAC and 38 cases underwent RCS. The characteristics of the study participants are shown in Table 1.

3.2. Primary outcome: Occurrence of Postpartum Depression. The incidence of EPDS $\geq 10$ at 48 hours after delivery in control and experiment group, respectively, was 42 of 159 (26.42\%) vs 22 of 259 (8.49\%) under TOLAC. It was significantly lower in parturients who received epidural labor analgesia than those who did not receive epidural labor analgesia $(P<0.001)$.

The incidence of EPDS $\geq 10$ at 42 days after delivery in control and experiment group, respectively, was 40 of 159 (25.16\%) vs 17 of 258 (6.59\%) under TOLAC. Obviously, the parturients who received epidural labor analgesia had a lower incidence of $E P D S \geq 10$ at 42 days after delivery $(P<0.001)$.

In addition, there was a significant correlation between the EPDS scores at 48 hours and 42 days after delivery (Pearson correlation coefficient $=0.657, P<0.001$ ).

3.3. Effects of Epidural Labor Analgesia. 36 (1.6\%) had VAS pain score above 5 at 10 minutes (after the first loading dose). No parturient had a VAS pain score above 5 at 30 minutes (after the supplemental dose). The VAS pain scores at $6 \mathrm{~cm}$ and $10 \mathrm{~cm}$ cervical dilation were significantly lower in those who received epidural analgesia than in those who did not. The effects of labor analgesia evaluated by parturients themselves were good in 243 cases (89.67\%), fair in 23 cases $(8.49 \%)$, and poor in 5 cases $(1.84 \%)$. The results of other perinatal and neonatal variables are described in Tables 2 and 3.

\subsection{Factors Associated with the Occurrence of Postpartum} Depression. When PPD at 48 hours was used as a dependent variable, univariate logistic regression analyses revealed that 7 of all the recorded parturient and neonatal variables were significant $(P<0.05)$ (Table 4$)$ for TOLAC. They were epidural analgesia, hospital name, family income, SAS, SSRS, platelets (PLT) (125-350), and perineum/cervical laceration. Multivariate logistic regression analysis identified 5 independent predictors; they were epidural analgesia, hospital name, SAS, SSRS, and PLT (125-350). Epidural analgesia during labor was significantly associated with a decreased risk of depression at 48 hours after delivery for TOLAC (OR, 0.209; 95\% CI, 0.096-0.429; $P<0.001$ ) (Table 4).

Furthermore, propensity score matching was used to reduce the potential selection bias and validate the results again. Whether or not "Epidural analgesia" was used as the dependent variable and other factors were used as the independent variables. We used 1:1 nearest neighbor matching selects for 107 individuals in the control group and 107 individuals in the analgesia group (66 unmatched). After matching, the logistic regression was performed. Univariate analysis was performed using the outcome of PPD at 48 hours (depression or no depression) as the dependent variable, and whether or not "Epidural analgesia" and "other confounding 


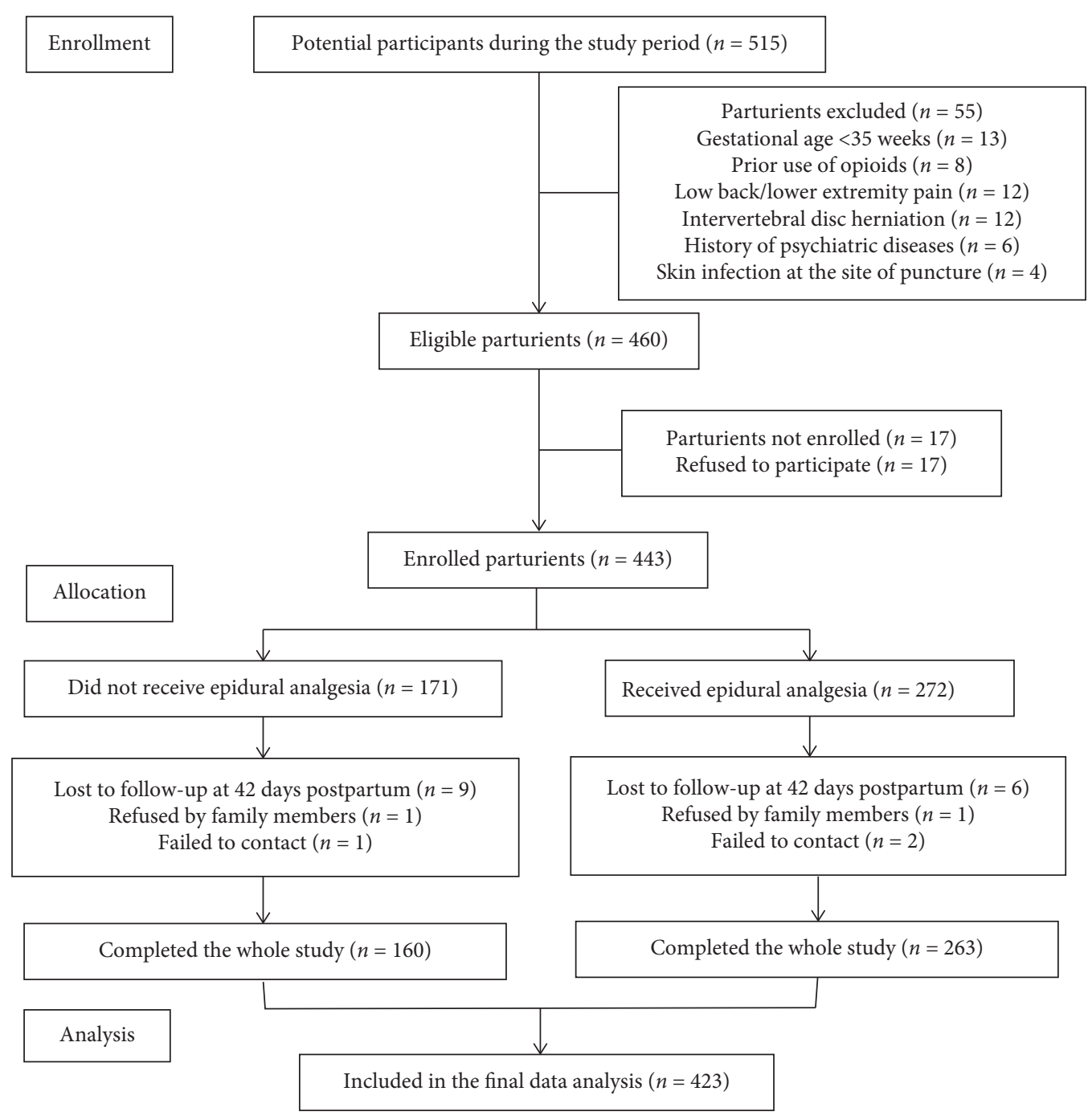

FIGURE 1

TABLE 3: Neonatal variables of parturients who completed the study for TOLAC.

\begin{tabular}{|c|c|c|c|c|c|c|}
\hline \multirow{2}{*}{ Neonatal outcomes } & \multicolumn{2}{|c|}{ TOLAC (CTRL) } & \multicolumn{2}{|c|}{ TOLAC (EXP) } & \multirow{2}{*}{ Statistical value } & \multirow{2}{*}{$P$ value } \\
\hline & $N($ All $)$ & Mean \pm SD or $n(\%)$ & $N($ All $)$ & Mean \pm SD or $n(\%)$ & & \\
\hline Weight & 148 & & 250 & & & 0.903 \\
\hline$<3500$ & & $114(77.03 \%)$ & & $190(76.00 \%)$ & & \\
\hline$\geq 3500$ & & $34(22.97 \%)$ & & $60(24.00 \%)$ & & \\
\hline Admission to neonatal ward after birth & 153 & $12(7.84 \%)$ & 256 & $20(7.81 \%)$ & & 1 \\
\hline 1 min Apgar & 159 & 0 (IRQ) & 261 & 0 (IRQ) & 12485.5 & 0.535 \\
\hline 5 min Apgar & 159 & 0 (IRQ) & 261 & 0 (IRQ) & 12542 & 0.292 \\
\hline
\end{tabular}

Data are mean $\pm \mathrm{SD}$, or $n(\%)$. Comparisons were made using Student's $t$-test or Wilcoxon rank sum test for nonnormally distributed variables. Comparisons were made using Pearson's chi-squared test and Fisher's exact test for proportions.

factors" as the independent variables. Factors with $P<0.05$ were included in the multivariate model, and stepwise regression was performed according to the AIC (Akaike information criterion) minimum criteria. 4 independent risk factors were obtained, and they were epidural analgesia, SAS, SSRS, and PLT (125-350); (Table 5).

Therefore, the common independent influencing factors of PPD at 48 hours in the TOLAC population before and after propensity matching were epidural analgesia, SAS, SSRS, and PLT (125-350) (Figure 2).

When PPD at 42 days was used as a dependent variable, univariate analyses revealed that 9 of all the recorded parturient and neonatal variables were significant $(P<0.05)$ (Table 6) for TOLAC. They were epidural analgesia, anxiety and depression during pregnancy, unplanned pregnancy, changes in marital relationship during pregnancy, SAS, 
TABLE 4: Univariate and multivariate analysis of PPD in TOLAC 48 hours after delivery.

\begin{tabular}{|c|c|c|c|c|}
\hline \multirow{2}{*}{$\begin{array}{l}\text { Variable } \\
\text { Independent }\end{array}$} & \multicolumn{2}{|r|}{ Univariate } & \multicolumn{2}{|c|}{ Multivariate $(n=369)$} \\
\hline & $P$ value & OR $(95 \% \mathrm{CI})$ & $P$ value & OR $(95 \% \mathrm{CI})$ \\
\hline Epidural analgesia & $<0.001$ & $0.259(0.145-0.449)$ & $<0.001$ & $0.209(0.096-0.429)$ \\
\hline $\begin{array}{l}\text { Hospital name } \\
\text { MCH } \\
\text { BA } \\
\text { LG }\end{array}$ & $\begin{array}{l}0.705 \\
0.049\end{array}$ & $\begin{array}{c}1 \text { (reference) } \\
0.862(0.377-1.785) \\
0.299(0.071-0.856)\end{array}$ & $\begin{array}{l}0.224 \\
0.069\end{array}$ & $\begin{array}{l}1.941(0.638-5.561) \\
0.286(0.060-0.975)\end{array}$ \\
\hline $\begin{array}{l}\text { General information } \\
\text { Age (year) } \\
\text { Gestational age (day) } \\
\text { BMI }\left(\mathrm{kg} / \mathrm{m}^{2}\right) \\
\text { Maternal education }>12 \mathrm{y} \\
\text { Husband education }>12 \mathrm{y} \\
\text { Housewives } \\
\text { Family income }(¥ / \mathrm{mo})^{*} \\
\leq 10,000 \\
10,001-20,000 \\
>20,000\end{array}$ & $\begin{array}{c}0.816 \\
0.253 \\
0.38 \\
0.301 \\
0.235 \\
0.713\end{array}$ & $\begin{array}{c}0.992(0.923-1.066) \\
1.017(0.991-1.050) \\
0.958(0.869-1.049) \\
0.736(0.416-1.338) \\
0.694(0.386-1.293) \\
1.190(0.430-2.821) \\
1 \text { (reference) } \\
0.475(0.222-1.039) \\
0.382(0.183-0.817)\end{array}$ & & \\
\hline $\begin{array}{l}\text { History of depression and trauma } \\
\text { Impact of childbirth on work or re-employment }\end{array}$ & $\begin{array}{ll}0.086 \\
0.456 \\
\end{array}$ & \begin{tabular}{|c|}
$.645(0.667-47.762)$ \\
$1.476(0.475-3.838)$ \\
\end{tabular} & & \\
\hline $\begin{array}{l}\text { Maternity leave time } \\
\text { No } \\
\text { Legal time } \\
\text { Full-time }\end{array}$ & $\begin{array}{l}0.987 \\
0.987\end{array}$ & $\begin{array}{c}1 \text { (reference) } \\
2517827.629(0.000-\mathrm{NA}) \\
3841697.685(0.000-\mathrm{NA})\end{array}$ & & \\
\hline $\begin{array}{l}\text { Anxiety and depression during pregnancy } \\
\text { Cigarettes, alcohol, long-term medication } \\
\text { Whether the husband is satisfied with the baby's sex }\end{array}$ & $\begin{array}{l}0.115 \\
0.408 \\
0.187\end{array}$ & \begin{tabular}{|c|}
$1.543(0.896-2.642)$ \\
$2.770(0.128-29.334)$ \\
$2.259(0.781-9.581)$
\end{tabular} & & \\
\hline $\begin{array}{l}\text { Caring health knowledge during pregnancy } \\
\text { (1) Routine obstetric examination } \\
\text { (2) Attend maternity classes } \\
\text { (3) Learn about parenting through cell phones or } \\
\text { books }\end{array}$ & $\begin{array}{l}0.287 \\
0.062\end{array}$ & $\begin{array}{l}0.531(0.178-1.948) \\
0.581(0.323-1.015) \\
0.720(0.369-1.498)\end{array}$ & & \\
\hline Unplanned pregnancy & 0.052 & $1.706(0.992-2.923)$ & & \\
\hline Whether the maternal is the only child in one's family & 0.743 & $1.138(0.497-2.367)$ & & \\
\hline Changes in marital relationship during pregnancy & 0.05 & $11.226(1.060-243.732)$ & & \\
\hline SAS & $<0.001$ & $1.092(1.045-1.142)$ & 0.003 & $1.093(1.031-1.162)$ \\
\hline SSRS & $<0.001$ & $0.895(0.858-0.932)$ & 0.004 & $0.932(0.887-0.977)$ \\
\hline MMSE & 0.377 & $1.118(0.872-1.431)$ & & \\
\hline $\begin{array}{l}\text { Prepartum Laboratory test } \\
\text { HGB (g/L: 115-150) } \\
\text { PLT (125-350) }\end{array}$ & $\begin{array}{l}0.085 \\
0.002\end{array}$ & $\begin{array}{l}1.017(0.998-1.037) \\
0.992(0.987-0.997)\end{array}$ & 0.017 & $0.992(0.986-0.998)$ \\
\hline Initiating lactation period (hours) & 0.273 & $1.011(0.990-1.030)$ & & \\
\hline Delivery outcome & & & & \\
\hline Mode of delivery (Cesarean VS VBAC) & 0.503 & $1.242(0.640-2.297)$ & & \\
\hline Episiotomy & 0.278 & $0.718(0.387-1.289)$ & & \\
\hline Perineum/Cervical laceration & 0.01 & $2.128(1.209-3.808)$ & 0.119 & $1.715(0.873-3.411)$ \\
\hline Feeding patterns within 48 hours (milk VS breast) & 0.169 & $0.241(0.013-1.191)$ & & \\
\hline $\begin{array}{l}\text { Feeding amounts within } 48 \text { hours (Abnormal VS } \\
\text { normal) }\end{array}$ & 0.747 & $0.814(0.187-2.500)$ & & \\
\hline Neonatal weight $\geq 3500$ & 0.086 & $1.680(0.916-3.003)$ & & \\
\hline Admission to neonatal ward after birth & 0.324 & $0.541(0.127-1.587)$ & & \\
\hline
\end{tabular}

BMI: body mass index; VAS: visual analog scale; SAS: Self-Rating Anxiety Scale; SSRS: Social Support Rating Scale; MMSE: mini-mental state examination; HGB: hemoglobin; PLT: platelet; $¥$ : Chinese Yuan. Hosmer and Lemeshow goodness of fit (GOF) test; X-squared $(\chi 2)=8.476, \mathrm{df}=8, P$ value $=0.388$. McFadden's pseudo- $\mathrm{R}$ squared $=0.206$. Cox and Snell pseudo- $\mathrm{R}$ squared $=0.157$. Nagelkerke pseudo- $\mathrm{R}$ squared $=0.279$. 
TABLE 5: Univariate and multivariate analysis of PPD in TOLAC 48 hours after delivery matched by PSM.

\begin{tabular}{|c|c|c|c|c|}
\hline \multirow{2}{*}{$\begin{array}{l}\text { Variable } \\
\text { Independent }\end{array}$} & \multicolumn{2}{|r|}{ Univariate $(n=214)$} & \multicolumn{2}{|c|}{ Multivariate $(n=214)$} \\
\hline & $P$ value & OR $(95 \% \mathrm{CI})$ & $P$ value & OR $(95 \% \mathrm{CI})$ \\
\hline Epidural analgesia & $<0.001$ & $0.257(0.117-0.528)$ & 0.006 & $\begin{array}{c}0.327 \\
(0.143-0.708)\end{array}$ \\
\hline $\begin{array}{l}\text { Hospital name } \\
\text { MCH } \\
\text { BA } \\
\text { LG }\end{array}$ & $\begin{array}{c}0.18 \\
0.295\end{array}$ & $\begin{array}{c}1 \text { (reference) } \\
0.546(0.210-1.257) \\
0.328(0.018-1.799) \\
\end{array}$ & & \\
\hline $\begin{array}{l}\text { General information } \\
\text { Age (year) } \\
\text { Gestational age (day) } \\
\text { BMI }\left(\mathrm{kg} / \mathrm{m}^{2}\right) \\
\text { Maternal education }>12 \mathrm{y} \\
\text { Husband education }>12 \mathrm{y} \\
\text { Housewives } \\
\text { Family income }(¥ / \mathrm{mo})^{*} \\
\leq 10000 \\
10,001-20,000 \\
>20,000\end{array}$ & $\begin{array}{c}0.782 \\
0.46 \\
0.684 \\
0.464 \\
0.104 \\
0.699\end{array}$ & $\begin{array}{c}0.987(0.896-1.086) \\
1.012(0.986-1.049) \\
0.976(0.864-1.093) \\
0.771(0.388-1.571) \\
0.556(0.276-1.145) \\
1.234(0.385-3.373) \\
1 \text { (reference) } \\
0.524(0.209-1.334) \\
0.291(0.117-0.733)\end{array}$ & & \\
\hline History of depression and trauma & 0.588 & $1.953(0.090-20.855)$ & & \\
\hline Impact of childbirth on work or re-employment & 0.517 & $1.429(0.440-3.989)$ & & \\
\hline $\begin{array}{l}\text { Maternity leave time } \\
\text { No } \\
\text { Legal time } \\
\text { Full-time }\end{array}$ & $\begin{array}{l}0.989 \\
0.988\end{array}$ & $\begin{array}{c}1 \text { (reference) } \\
3510585.584(0.000-\mathrm{NA}) \\
5397020.941(0.000-\mathrm{NA})\end{array}$ & & \\
\hline Anxiety and depression during pregnancy & 0.55 & $1.228(0.621-2.398)$ & & \\
\hline Cigarettes, alcohol, long-term medication & 0.337 & $3.930(0.153-100.739)$ & & \\
\hline Whether the husband is satisfied with the baby's sex & 0.303 & $2.975(0.555-55.127)$ & & \\
\hline $\begin{array}{l}\text { Caring health knowledge during pregnancy } \\
\text { (1) Routine obstetric examination } \\
\text { (2) Attend maternity classes } \\
\text { (3) Learn about parenting through cell phones } \\
\text { or books }\end{array}$ & $\begin{array}{c}0.24 \\
0.046\end{array}$ & $\begin{array}{l}0.414(0.098-2.084) \\
0.483(0.230-0.968) \\
0.972(0.440-2.324)\end{array}$ & & \\
\hline Unplanned pregnancy & 0.065 & $1.891(0.955-3.724)$ & & \\
\hline $\begin{array}{l}\text { Whether the maternal is the only child in one's } \\
\text { family }\end{array}$ & 0.686 & $1.209(0.451-2.912)$ & & \\
\hline Changes in marital relationship during pregnancy & 0.337 & $3.930(0.153-100.739)$ & & \\
\hline SAS & $<0.001$ & $1.155(1.082-1.240)$ & 0.003 & $\begin{array}{c}1.118 \\
(1.041-1.207)\end{array}$ \\
\hline SSRS & $<0.001$ & $0.914(0.868-0.959)$ & 0.01 & $\begin{array}{c}0.930 \\
(0.879-0.982)\end{array}$ \\
\hline MMSE & 0.702 & $0.943(0.694-1.274)$ & & \\
\hline $\begin{array}{l}\text { Prepartum Laboratory test } \\
\text { HGB (g/L: 115-150) }\end{array}$ & 0.77 & $0.995(0.963-1.028)$ & & \\
\hline PLT (125-350) & 0.02 & $0.992(0.986-0.999)$ & 0.017 & $\begin{array}{c}0.991 \\
(0.983-0.998)\end{array}$ \\
\hline Initiating lactation period (hours) & 0.236 & $1.019(0.987-1.050)$ & & \\
\hline Delivery outcome & & & & \\
\hline Mode of delivery (Cesarean VS VBAC) & 0.337 & $0.580(0.164-1.602)$ & & \\
\hline Episiotomy & 0.712 & $0.878(0.434-1.730)$ & & \\
\hline Perineum/Cervical laceration & 0.067 & $1.874(0.962-3.720)$ & & \\
\hline Feeding patterns within 48 hours (milk VS breast) & 0.988 & $\begin{array}{c}0.000 \\
(\mathrm{NA}-63246344962664952524800406.000) \\
\end{array}$ & & \\
\hline $\begin{array}{l}\text { Feeding amounts within } 48 \text { hours (Abnormal VS } \\
\text { normal) }\end{array}$ & 0.696 & $1.309(0.281-4.616)$ & & \\
\hline Neonatal weight $\geq 3500$ & 0.279 & $1.507(0.700-3.124)$ & & \\
\hline Admission to neonatal ward after birth & 0.311 & $0.458(0.071-1.697)$ & & \\
\hline
\end{tabular}

PSM: propensity score matching. Data had been matched by using propensity score matching with $1: 1$ nearest neighbor matching. Hosmer and Lemeshow goodness of fit $(\mathrm{GOF})$ test; $\mathrm{X}$-squared $(\chi 2)=3.728, \mathrm{df}=8, P$ value $=0.881$. McFadden's pseudo- $\mathrm{R}$ squared $=0.192$. Cox and Snell pseudo-R squared $=0.177$. Nagelkerke pseudo-R squared $=0.278$. 


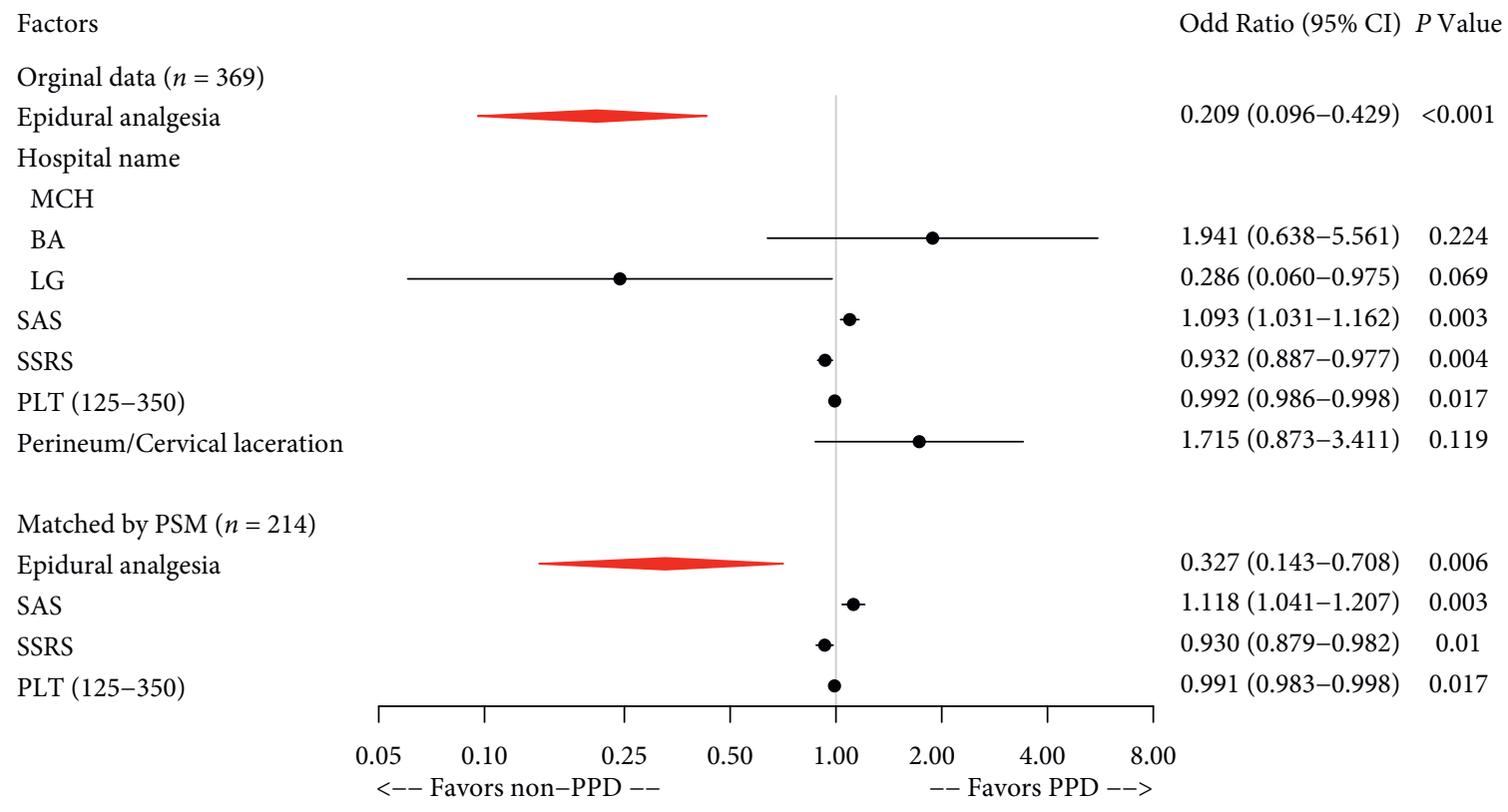

Figure 2

SSRS, HGB (g/L: 115-150), perineum/cervical laceration, and discomfort within 42 days. Multivariate logistic regression analysis identified 3 independent predictors, and they were epidural analgesia, SSRS, and discomfort within 42 days. Epidural analgesia during labor was significantly associated with a decreased risk of depression at 42 days after delivery for TOLAC (OR, 0.235; 95\% CI, 0.113-0.469; $P<0.001$ ) (Table 6).

Furthermore, propensity score matching was used to reduce the potential selection bias and validate the results again. Whether or not "Epidural analgesia" was used as the dependent variable and other factors were used as the independent variables. We used 1:1 nearest neighbor matching selects for 107 individuals in the control group and 107 individuals in the analgesia group (66 unmatched). After matching, the logistic regression was performed. Univariate analysis was performed using the outcome of PPD at 48 days (depression or no depression) as the dependent variable, and whether or not "Epidural analgesia" and "other confounding factors" as the independent variables. Factors with $P<0.05$ were included in the multivariate model, and stepwise regression was performed according to the AIC minimum criteria. 4 independent risk factors were obtained, and they were epidural analgesia, SAS, SSRS, and discomfort within 42 days (Table 7 ).

Therefore, the common independent influencing factors of PPD at 42 days in the TOLAC population before and after propensity matching were epidural analgesia and discomfort within 42 days (Figure 3 ).

3.5. Effect of Prediction of PPD for TOLAC in 48 Hours. We use the two multivariate logistic regressions to predict PPD in TOLAC. The model without PSM showed that AUC (area under the curve) $=0.793$, 95\% CI: 0.719-0.867, sensitivity $=0.722$, specificity $=0.818$, positive predictive value $=0.402$, and negative predictive value $=0.945$. The model with PSM showed that AUC (area under the curve) $=$ $0.788,95 \%$ CI: $0.714-0.863$, sensitivity $=0.864$, specificity $=0.641$, positive predictive value $=0.384$, and negative predictive value $=0.948$ (Figure 4$)$.

3.6. Effect of Prediction of PPD for TOLAC in 42 Days. We use the two multivariate logistic regressions to predict PPD in TOLAC. The model without PSM showed that AUC (area under the curve) $=0.833,95 \%$ CI: 0.774-0.892, sensitivity $=0.780$, specificity $=0.795$, positive predictive value $=0.361$, and negative predictive value $=0.960$. The model with PSM showed that AUC (area under the curve) = 0.844, 95\% CI: 0.786-0.865, sensitivity $=0.811$, specificity $=0.797$, positive predictive value $=0.455$, and negative predictive value $=0.953($ Figure 5$)$.

\section{Discussion}

In the study, the incidence of PPD was reported from $20.3 \%$ to $29.5 \%$ aiming at nulliparous $[23,25]$, whereas the incidence rate of pluripara in this study was $13.5 \%$ in TOLAC which is much lower than that of the nulliparous, and reasons are not clear.

This study drew the conclusion that epidural labor analgesia is correlative with a decreased risk of EPDS in TOLAC, whereas the discomfort within 42 days, SAS score, and a high EPDS score early after delivery were associated with increased risks of EPDS. In the experimental group, more parturients received VBAC than RCS, which may cause the low incidence of high EPDS scores. The cause of PPD is often complex and has many influencing factors $[26,27]$. For most women, labor is inevitably accompanied by intense pain and stress [28]. There were some studies which reported a correlation of the level of labor pain and 
TABLE 6: Univariate and multivariate analysis of PPD in TOLAC 42 days after delivery.

\begin{tabular}{|c|c|c|c|c|}
\hline \multirow{2}{*}{$\begin{array}{l}\text { Variable } \\
\text { Independent }\end{array}$} & \multicolumn{2}{|r|}{ Univariate } & \multicolumn{2}{|c|}{ Multivariate $(n=386)$} \\
\hline & $P$ value & OR $(95 \% \mathrm{CI})$ & $P$ value & OR $(95 \% \mathrm{CI})$ \\
\hline Epidural analgesia & $<0.001$ & $0.210(0.112-0.380)$ & $<0.001$ & $0.235(0.113-0.469)$ \\
\hline $\begin{array}{l}\text { Hospital name } \\
\text { MCH } \\
\text { BA } \\
\text { LG }\end{array}$ & $\begin{array}{c}0.49 \\
0.078 \\
\end{array}$ & $\begin{array}{c}1 \text { (reference) } \\
0.742(0.293-1.638) \\
0.337(0.080-0.970) \\
\end{array}$ & & \\
\hline $\begin{array}{l}\text { General information } \\
\text { Age (year) } \\
\text { Gestational age (day) } \\
\text { BMI }\left(\mathrm{kg} / \mathrm{m}^{2}\right) \\
\text { Maternal education }>12 \mathrm{y} \\
\text { Husband education }>12 \mathrm{y} \\
\text { Housewives } \\
\text { Family income }(¥ / \mathrm{mo})^{*} \\
\leq 10,000 \\
10,001-20,000 \\
>20,000\end{array}$ & $\begin{array}{l}0.764 \\
0.413 \\
0.306 \\
0.714 \\
0.683 \\
0.499\end{array}$ & $\begin{array}{c}1.012(0.938-1.092) \\
1.012(0.987-1.045) \\
0.949(0.855-1.044) \\
0.890(0.484-1.702) \\
0.873(0.464-1.728) \\
1.378(0.496-3.287) \\
1 \text { (reference) } \\
0.715(0.307-1.774) \\
0.618(0.275-1.494)\end{array}$ & & \\
\hline $\begin{array}{l}\text { History of depression and trauma } \\
\text { Impact of childbirth on work or re-employment }\end{array}$ & 0.065 & $\begin{array}{c}6.473(0.764-54.851) \\
1.705(0.547-4.456) \\
\end{array}$ & & \\
\hline $\begin{array}{l}\text { Maternity leave time } \\
\text { No } \\
\text { Legal time } \\
\text { Full-time }\end{array}$ & $\begin{array}{l}0.775 \\
0.719\end{array}$ & $\begin{array}{c}1 \text { (reference) } \\
0.731(0.119-14.063) \\
1.486(0.240-28.690) \\
\end{array}$ & & \\
\hline $\begin{array}{l}\text { Anxiety and depression during pregnancy } \\
\text { Cigarettes, alcohol, long-term medication } \\
\text { Whether the husband is satisfied with the baby's sex }\end{array}$ & \begin{tabular}{c|}
0.018 \\
0.35 \\
0.276
\end{tabular} & $\begin{array}{c}1.979(1.125-3.487) \\
3.170(0.146-33.618) \\
1.963(0.676-8.341)\end{array}$ & & \\
\hline $\begin{array}{l}\text { Caring health knowledge during pregnancy } \\
\text { (1) Routine obstetric examination } \\
\text { (2) Attend maternity classes } \\
\text { (3) Learn about parenting through cell phones } \\
\text { or books }\end{array}$ & $\begin{array}{l}0.881 \\
0.254\end{array}$ & $\begin{array}{l}1.122(0.303-7.273) \\
0.713(0.392-1.264)\end{array}$ & & \\
\hline Unplanned pregnancy & 0.027 & $1.891(1.074-3.329)$ & & \\
\hline Whether the maternal is the only child in one's family & 0.939 & $0.968(0.382-2.142)$ & & \\
\hline Changes in marital relationship during pregnancy & 0.038 & $12.873(1.214-279.754)$ & & \\
\hline SAS & 0.001 & $1.079(1.031-1.130)$ & 0.097 & $1.051(0.991-1.114)$ \\
\hline SSRS & $<0.001$ & $0.922(0.885-0.961)$ & 0.017 & $0.945(0.901-0.990)$ \\
\hline MMSE & 0.991 & $0.998(0.768-1.293)$ & & \\
\hline $\begin{array}{l}\text { Prepartum Laboratory test } \\
\text { HGB (g/L: 115-150) } \\
\text { PLT (125-350) }\end{array}$ & $\begin{array}{l}0.015 \\
0.111\end{array}$ & $\begin{array}{l}1.027(1.006-1.051) \\
0.996(0.990-1.001)\end{array}$ & 0.08 & $1.027(0.997-1.058)$ \\
\hline Initiating lactation period (hours) & 0.104 & $1.016(0.996-1.036)$ & & \\
\hline Delivery outcome & & & & \\
\hline Mode of delivery (Cesarean VS VBAC) & 0.401 & $1.325(0.667-2.503)$ & & \\
\hline Episiotomy & 0.34 & $0.735(0.382-1.362)$ & & \\
\hline Perineum/Cervical laceration & 0.015 & $2.121(1.166-3.931)$ & 0.076 & $1.850(0.942-3.689)$ \\
\hline Feeding patterns within 48 hours (milk VS breast) & 0.234 & $1.887(0.597-5.055)$ & & \\
\hline $\begin{array}{l}\text { Feeding amounts within } 48 \text { hours (Abnormal VS } \\
\text { normal) }\end{array}$ & 0.474 & $0.581(0.091-2.080)$ & & \\
\hline Neonatal weight $\geq 3500$ & 0.296 & $1.403(0.727-2.603)$ & & \\
\hline Admission to neonatal ward after birth & 0.451 & $0.625(0.146-1.839)$ & & \\
\hline Discomfort within 42 days & $<0.001$ & $7.692(4.108-14.466)$ & $<0.001$ & $5.934(2.823-12.524)$ \\
\hline
\end{tabular}

Hosmer and Lemeshow goodness of fit (GOF) test; X-squared $(\chi 2)=10.156, \mathrm{df}=8, P$ value $=0.254$. McFadden's pseudo-R squared $=0.230$. Cox and Snell pseudo-R squared $=0.162$. Nagelkerke pseudo-R squared $=0.302$. 
TABLE 7: Univariate and multivariate analysis of PPD in TOLAC 42 days after delivery matched by PSM.

\begin{tabular}{|c|c|c|c|c|}
\hline \multirow{2}{*}{$\begin{array}{l}\text { Variable } \\
\text { Independent }\end{array}$} & \multicolumn{2}{|c|}{ Univariate $(n=214)$} & \multicolumn{2}{|c|}{ Multivariate $(n=214)$} \\
\hline & $P$ value & OR $(95 \% \mathrm{CI})$ & $P$ value & OR $(95 \% \mathrm{CI})$ \\
\hline Epidural analgesia & $<0.001$ & $0.146(0.053-0.344)$ & 0.003 & $0.224(0.078-0.563)$ \\
\hline \multicolumn{5}{|l|}{ Hospital name } \\
\hline $\mathrm{MCH}$ & & 1 (reference) & & \\
\hline BA & 0.136 & $0.465(0.151-1.179)$ & & \\
\hline LG & 0.391 & $0.400(0.021-2.208)$ & & \\
\hline \multicolumn{5}{|l|}{ General information } \\
\hline Age (year) & 0.822 & $0.988(0.892-1.095)$ & & \\
\hline Gestational age (day) & 0.582 & $1.009(0.983-1.048)$ & & \\
\hline BMI $\left(\mathrm{kg} / \mathrm{m}^{2}\right)$ & 0.85 & $0.988(0.867-1.115)$ & & \\
\hline Maternal education $>12 \mathrm{y}$ & 0.63 & $0.832(0.400-1.796)$ & & \\
\hline Husband education $>12 \mathrm{y}$ & 0.201 & $0.611(0.290-1.329)$ & & \\
\hline Housewives & 0.343 & $1.688(0.520-4.712)$ & & \\
\hline \multicolumn{5}{|l|}{ Family income $(¥ / \mathrm{mo})^{*}$} \\
\hline$\leq 10000$ & & 1 (reference) & & \\
\hline $10,001-20,000$ & 0.305 & $0.593(0.221-1.664)$ & & \\
\hline$>20,000$ & 0.082 & $0.419(0.159-1.156)$ & & \\
\hline History of depression and trauma & 0.473 & $2.431(0.111-26.034)$ & & \\
\hline Impact of childbirth on work or re-employment & 0.565 & $1.411(0.382-4.228)$ & & \\
\hline \multicolumn{5}{|l|}{ Maternity leave time } \\
\hline No & & 1 (reference) & & \\
\hline Legal time & 0.527 & $0.474(0.057-9.860)$ & & \\
\hline Full-time & 0.929 & $0.900(0.108-18.805)$ & & \\
\hline Anxiety and depression during pregnancy & 0.053 & $2.027(0.993-4.185)$ & & \\
\hline Cigarettes, alcohol, long-term medication & 0.266 & $4.889(0.190-125.562)$ & & \\
\hline Whether the husband is satisfied with the baby's sex & 0.412 & $2.386(0.443-44.292)$ & & \\
\hline \multicolumn{5}{|l|}{ Caring health knowledge during pregnancy } \\
\hline (1) Routine obstetric examination & 0.717 & $1.482(0.253-28.152)$ & & \\
\hline (2) Attend maternity classes & 0.487 & $0.773(0.366-1.584)$ & & \\
\hline $\begin{array}{l}\text { (3) Learn about parenting through cell phones } \\
\text { or books }\end{array}$ & 0.116 & $2.409(0.891-8.431)$ & & \\
\hline Unplanned pregnancy & 0.085 & $1.885(0.910-3.879)$ & & \\
\hline Whether the maternal is the only child in one's family & 0.994 & $0.996(0.317-2.623)$ & & \\
\hline Changes in marital relationship during pregnancy & 0.266 & $4.889(0.190-125.562)$ & & \\
\hline SAS & $<0.001$ & $1.145(1.069-1.233)$ & 0.03 & $1.090(1.010-1.182)$ \\
\hline SSRS & 0.007 & $0.933(0.886-0.980)$ & 0.132 & $0.957(0.904-1.014)$ \\
\hline MMSE & 0.729 & $0.944(0.677-1.309)$ & & \\
\hline \multicolumn{5}{|l|}{ Prepartum Laboratory test } \\
\hline HGB (g/L: 115-150) & 0.377 & $1.015(0.982-1.049)$ & & \\
\hline PLT $(125-350)$ & 0.706 & $0.999(0.992-1.005)$ & & \\
\hline Initiating lactation period (hours) & 0.279 & $1.016(0.985-1.046)$ & & \\
\hline \multicolumn{5}{|l|}{ Delivery outcome } \\
\hline Mode of delivery (Cesarean VS VBAC) & 0.653 & $0.773(0.216-2.166)$ & & \\
\hline Episiotomy & 0.531 & $0.790(0.368-1.631)$ & & \\
\hline Perineum/Cervical laceration & 0.091 & $1.862(0.912-3.889)$ & & \\
\hline Feeding patterns within 48 hours (milk VS breast) & 0.195 & $2.263(0.586-7.403)$ & & \\
\hline $\begin{array}{l}\text { Feeding amounts within } 48 \text { hours (Abnormal VS } \\
\text { normal) }\end{array}$ & 0.953 & $0.954(0.143-3.824)$ & & \\
\hline Neonatal weight $\geq 3500$ & 0.563 & $1.269(0.545-2.775)$ & & \\
\hline Admission to neonatal ward after birth & 0.199 & $0.261(0.014-1.338)$ & & \\
\hline Discomfort within 42 days & $<0.001$ & $7.171(3.162-16.468)$ & 0.002 & $4.348(1.749-10.861)$ \\
\hline
\end{tabular}

PSM: propensity score matching. Data had been matched by using propensity score matching with $1: 1$ nearest neighbor matching. Hosmer and Lemeshow goodness of fit $(\mathrm{GOF})$ test; $\mathrm{X}$-squared $(\chi 2)=10.081, \mathrm{df}=7, P$ value $=0.188$. McFadden's pseudo-R squared $=0.229$. Cox and Snell pseudo-R squared $=0.190$. Nagelkerke pseudo-R squared $=0.316$.

the risk of PPD $[14,15]$. Moreover, the labor pain evaluated in the early postpartum period (from 36 hours to 3 days postpartum) was found to be associated with PPD [14, 15]. In our study, the labor pain was evaluated during labor at 5 stages and the pain scores were significantly lower in parturients who received epidural analgesia than those who did not (Table 2), and corresponding incidence rate of PPD is relatively lower. In this study, although remifentanil could rapidly cross the placenta into the fetal circulation, we did not use remifentanil for the method of application of 
Factors

Odd Ratio (95\%CI) $\quad P$ Value

Orginal data $(n=386)$

Epidural analgesia

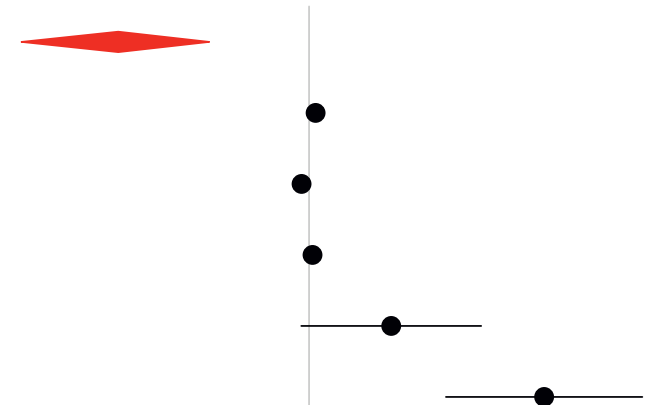

$0.235(0.113-0.469)<0.001$

SAS

$1.051(0.991-1.114) \quad 0.097$

SSRS

$0.945(0.901-0.990) \quad 0.017$

HGB (g/L:115-150)

Perineum/Cervical laceration

$1.027(0.997-1.058) \quad 0.08$

$1.850(0.942-3.689) \quad 0.076$

Discomfort within 42 days

Matched by PSM $(n=214)$

Epidural analgesia

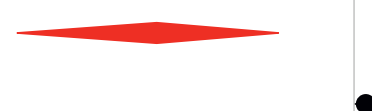

$0.224(0.078-0.563) \quad 0.003$

SAS

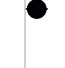

$1.090(1.010-1.182) \quad 0.03$

SSRS

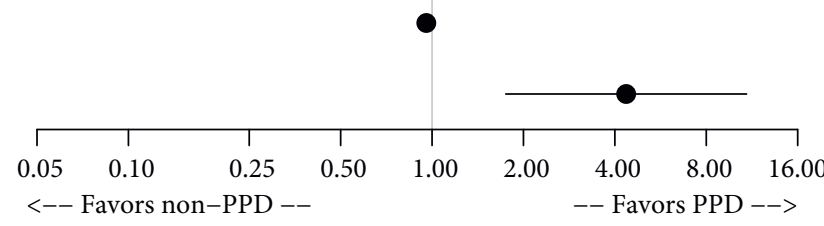

$0.957(0.904-1.014) \quad 0.132$

$4.348(1.749-10.861) \quad 0.002$

Discomfort within 42 days

Figure 3

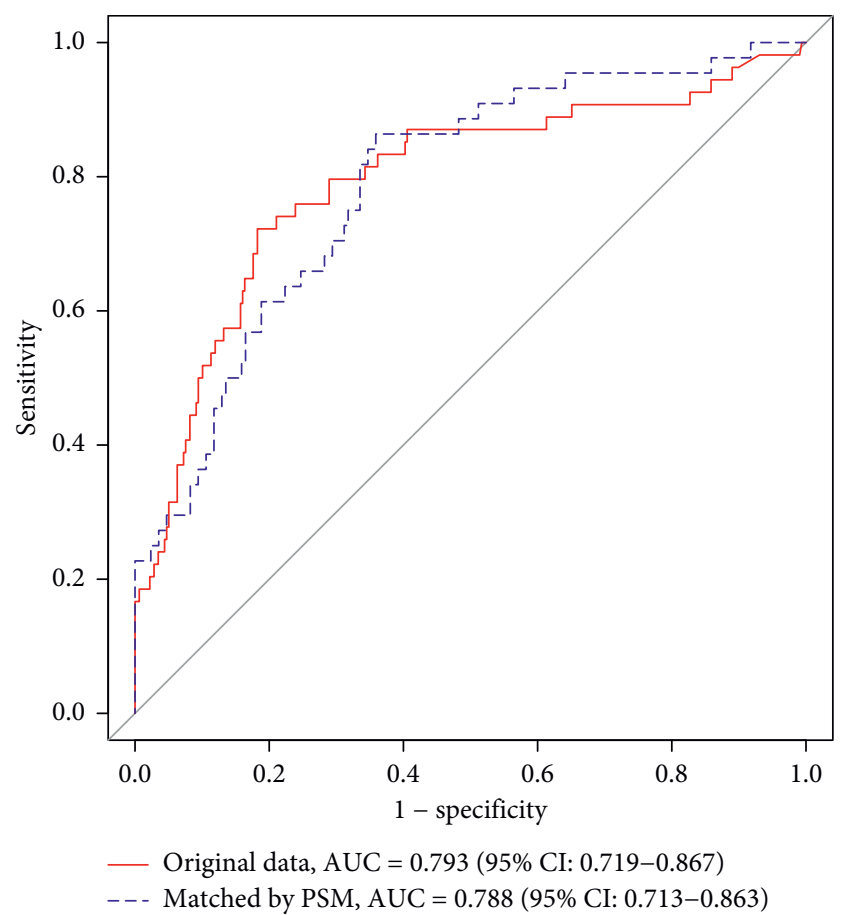

FIGURE 4

remifentanil may be associated with the impairment of neonatal outcome [29]; the effects of labor analgesia was evaluated by parturients themselves, and 243 cases (89.67\%)

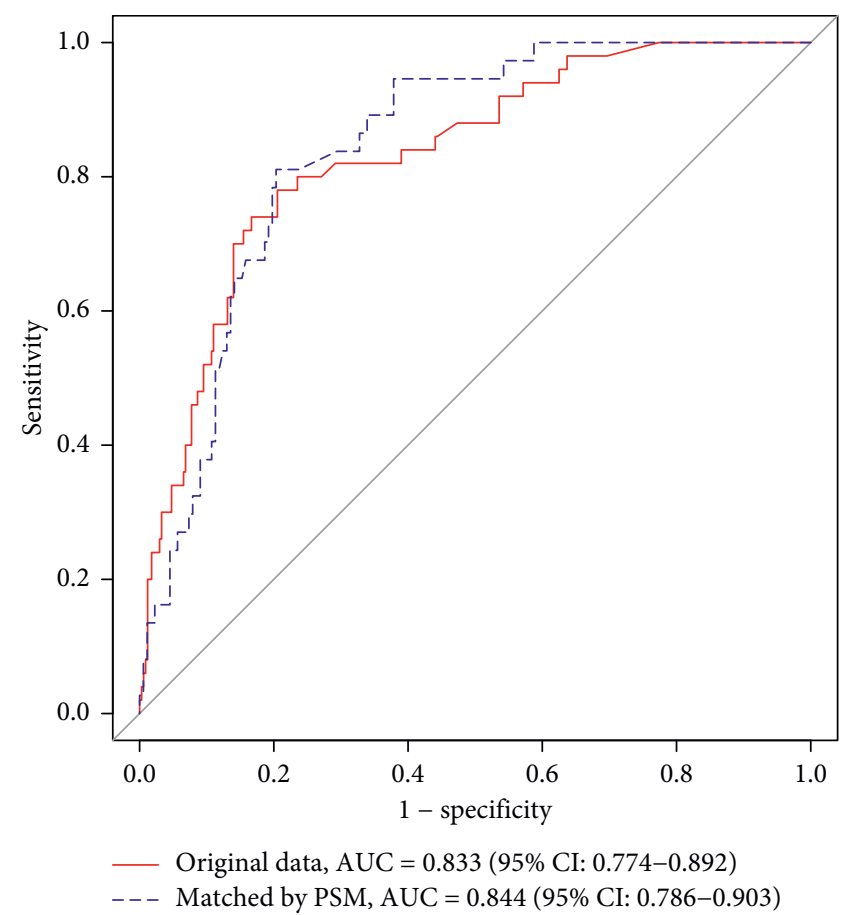

FIGURE 5

felt good, 23 cases (8.49\%) felt fair, and 5 cases (1.84\%) felt poor. Labor analgesia can minimize pain of pregnant women, provide humanized medical services to pregnant 
women, help parturients establish confidence in natural labor, improve the rate of natural childbirth, reduce the adverse effects of pain on mother and baby, increase the rate of eutocia, increase blood flow to the placenta, improve fetal oxygen supply, relieve adverse reaction of labor pain, reduce or eliminate the parturients' childbirth pain, reduce maternal unnecessary physical consumption, maintain the dignity of parturients' childbirth, and let parturients enjoy the joy of child labor [30-32]. The overall painless labor analgesia rate of this study was $62.17 \%$. And Affiliated Shenzhen Maternity and Child Healthcare Hospital had a painless labor analgesia rate of 57.74\%, Bao'an Maternal and Child Health Hospital had a painless labor analgesia rate of 98\%, and Longgang District Maternity and Child Healthcare Hospital of Shenzhen City had a painless labor analgesia rate of $47.17 \%$. The painless delivery rate of Bao'an Maternal and Child Health Hospital was so high, mainly because the hospital fully implemented the "painless hospital" construction and responded to the call of the World Health Organization to "improve the rate of painless delivery," as long as there was no contraindication to labor analgesia in the spinal canal after entering the delivery room. All women underwent painless delivery. If the mother refused to give birth painlessly, she could only go to other hospitals to give birth.

Besides the pain variables, the independent predictors of PPD were anxiety and depression during pregnancy [33], perceived stress, number of past stressful life events, lack of social support, history of depression, childhood maltreatment, and maternal nativity status. There is ample evidence that shows PPD has adverse effects on mothers, infants, and their families [34-37]. Mothers with depression are slow and insensitive in their interactions with children and show a higher incidence of negative behaviors such as smoking and not using car seat belt $[38,39]$. Mothers not only care about physiological needs of infants but also significantly influence the cognitive and social development. Therefore, it is not surprising that maternal depression is related with low cognitive and increased behavioral problems in infants and children. Emotions are often felt in the body (anxiety as stomach "butterflies," grief as "heartache") and associated with specific topographical body sites of sensations. Therefore, in this study, we used the discomfort within 42 days to describe the pluripara state and interestingly found that there was a close association between EPDS score and discomfort. Many parturients experienced varying degrees of discomfort located in the perineum, vagina, and breasts or severe headaches after giving birth. Many discomforts were not serious, but had an adverse effect on maternal mood. This suggests that the discomfort cannot be ignored. Physical discomfort can cause mental changes, such as PPD. Women with PPD are exquisitely sensitive to the massive gonadal steroid withdrawal that occurs at birth. This biological vulnerability interacts with predelivery risk factors for major depressive disorder (MDD) [40]. In a model including nearly 2000 female twins and analyzing occurrence of MDD lasting over a 1 year, 52\% of the variance of MDD was explained by 3 factors: [41] internalizing (early life onset of anxiety disorders), externalizing (conduct problems and substance abuse), and adversity (childhood maltreatment and interpersonal problems). SAS was used to evaluate the anxiety within 2 weeks before delivery which reflected internalizing factors [42]. SSRS assessed the social support situation of women [43]. In the current study, SAS score was a risk factor while SSRS score was a protective factor, which was consistent with existing literature.

The postpartum hemorrhage rate (defined as $<500 \mathrm{~mL}$ ) was reported as $2 \%$. This is extremely low. It may be because the Grade Three Class-A hospitals perform strict evaluation and monitoring of TOLAC maternity and carry out 1-on-1 midwifery. The exact reason why platelets become meaningful variables is unknown and can be verified by further clinical studies or animal experiments. In the epidural labor analgesia group, initial time of lactation was shorter, which was completely the benefit of labor analgesia for parturients, and labor analgesia reduced labor pain and reduced the release of stress hormone catecholamines so that the prolactin level was increased [44, 45]. About the influencing factor of episiotomy, the incident rate of it in the experiment group was higher than that of control group obviously, and the difference was statistically significant; it may be related to the extension of the first stage and the second stage. In this study, the time of the first stage and second stage in the experiment group was indeed longer than the control group, but the time was within the normal range, which is shown in Table 2. For the second stage of women with epidural labor analgesia, as long as the mother and infant were safe, the time of labor could be up to 3 hours [46]. Professor Shapiro, an obstetrician at Harvard Medical School, once said that as long as the mother and infant are safe, waiting is a virtue for the second stage. In this study, the time of labor was longer, but vaginal delivery was successful, which was exciting. At the same time, in the analysis of logistic regression of labor time in PPD, there was no statistical significance, which indicated that the labor time and episiotomy did not increase the incidence of PPD. The influential factor of perineum/ cervical laceration was still statistically significant at 48 hours and 42 days after delivery in single factor analysis and multivariate regression analysis, which could be seen in Figures 2 and 3. Interestingly, after performing propensity matching and control of confounding factors, it was not statistically significant. This could be explained that this variable was a covariate and did not act as an independent variable for PPD but acted as a risk factor with other variables.

In univariate analysis, participation in maternity classes was a meaningful variable, $P<0.05$. Although some hospitals started maternity schools early, the participation rate of pregnant women has not been high. In recent years, with the population of "eugenics policy" and the promotion of the benefits of painless delivery, the participation rate of maternity schools has increased significantly. This study focused on women who had given birth to a second child after a cesarean section; the second production method after cesarean section, breastfeeding (China used to mislead mothers that milk was more nutritious), postpartum care, psychology consultation, painless delivery, and so on are hot topics of concern for multiparous. So in this survey, the 
participation rate in maternity schools was higher than that in western countries. The rates of attendance at childbirth classes during pregnancy were $33.5 \%$ and $46.4 \%$ in the two groups, and there were statistically significant differences.

At present, there is no uniform screening time point for PPD, and the two commonly used screening time-points are within 4 weeks after delivery (Diagnostic and Statistical Manual of Mental Disorders-IV) and within 6 weeks after delivery (International Statistical Classification of Diseases and Related Health Problems-10) [47]. In addition, it has been suggested that PPD should not be screened in the first few days after delivery because symptoms are not fully developed [48]. However, high scores of antepartum or peripartum depression are strong predictors of PPD. In our study, EPDS was assessed at 48 hours and 42 days after delivery and the 42-day EPDS score was used for diagnosing initial screening of PPD. This study also found that a high early EPDS score was an independent predictor of PPD. It should be noted that most multiparous women delivering vaginally would have gone home by 48 hours in the UK which is different in China. The mother delivering vaginally can only be discharged from hospital 48-72 hours after delivery. During this period, the maternal blood routine, bleeding, urination, and lochia discharge were mainly observed. More importantly, in China, newborns can only be injected with Bacillus Calmette-Guerin after 48 hours, and the plantar blood can be collected after 72 hours. Therefore, the time of discharge from the hospital in China is also different from that in Western countries.

There were several limitations of this study. First, the parturients were grouped according to their decision. Second, analyzed laboring women were of the same ethnicity. The effect of region, culture, or ethnicity could not be excluded. Third, the diagnosis of PPD was not performed by psychiatrists. Although EPDS could be used to examine PPD, the effectiveness of Chinese parturients has been well confirmed [49-51]. Fourth, an observational study could not determine whether there was a causal relationship between epidural labor analgesia and the decreased risk of PPD. Last, the follow-up time was not long enough. New episodes of depression occur in $14.5 \%$ of women in the first 3 months after birth, and the 1-year period prevalence was a striking $21.9 \%$ (95\% CI, 15.1\%$30.0 \%$ ) [52]. If the follow-up time was prolonged to one year, the occurrence of the PPD might be higher. It could be of help to know the deeper effect on PPD.

\section{Conclusion}

It was found that epidural analgesia during labor may be associated with a decreased risk of PPD. Further study with a large sample size and a longer follow-up time is clearly needed to evaluate the impact of epidural analgesia on the occurrence of PPD.

\section{Data Availability}

The data used to support the findings of this study are included within the article.

\section{Conflicts of Interest}

The authors declare that there are no conflicts of interest regarding the publication of this article.

\section{Acknowledgments}

The authors thank Yu Lin (Statistician, Shenzhen Withsum Technology Limited, supported by the Shenzhen Science and Technology Plan, grant no. CKCY20180323174659823) for assistance with data analysis that greatly improved the manuscript. This work was supported by the SingChn Foundation.

\section{References}

[1] L. M. Howard, E. Molyneaux, C.-L. Dennis, T. Rochat, A. Stein, and J. Milgrom, "Non-psychotic mental disorders in the perinatal period," The Lancet, vol. 384, no. 9956, pp. 1775-1788, 2014.

[2] A. Esscher, B. Essén, E. Innala et al., "Suicides during pregnancy and 1 year postpartum in Sweden, 1980-2007," British Journal of Psychiatry, vol. 208, no. 5, pp. 462-469, 2016.

[3] American Psychiatric Association, Diagnostic and Statistical Manual of Mental Disorders (DSM- $\left.{ }^{\circledR}\right)$, American Psychiatric Pub, Philadelphia, PA, USA, 2013.

[4] World Health Organization, International Statistical Classification of Diseases and Related Health Problems, Vol. 1, World Health Organization, Geneva, Switzerland, 2004.

[5] R. M. Pearson, J. Evans, D. Kounali et al., "Maternal depression during pregnancy and the postnatal period," JAMA Psychiatry, vol. 70, no. 12, pp. 1312-1319, 2013.

[6] K. L. Wisner, D. K. Y. Sit, M. C. McShea et al., "Onset timing, thoughts of self-harm, and diagnoses in postpartum women with screen-positive depression findings," JAMA Psychiatry, vol. 70, no. 5, pp. 490-498, 2013.

[7] L.-1. Gao, S. W.-c. Chan, L. You, and X. Li, "Experiences of postpartum depression among first-time mothers in mainland China," Journal of Advanced Nursing, vol. 66, no. 2, pp. 303-312, 2010.

[8] L. Hou, "Cesarean delivery rate and indications in mainland China: a cross sectional study in 2011," Zhonghua Fu Chan Ke Za Zhi, vol. 49, no. 10, pp. 728-735, 2014.

[9] Y. Liu, X. Wang, L. Zou, Y. Ruan, and W. Zhang, “An analysis of variations of indications and maternal-fetal prognosis for caesarean section in a tertiary hospital of Beijing: a population-based retrospective cohort study," Medicine, vol. 96, no. 7, Article ID e5509, 2017.

[10] P. Lumbiganon, M. Laopaiboon, A. M. Gülmezoglu et al., "Method of delivery and pregnancy outcomes in Asia: the WHO global survey on maternal and perinatal health 20072008," The Lancet, vol. 375, no. 9713, pp. 490-499, 2010.

[11] H.-T. Li, S. Luo, L. Trasande et al., "Geographic variations and temporal trends in cesarean delivery rates in China, 20082014," JAMA, vol. 317, no. 1, pp. 69-76, 2017.

[12] C. G. Fawsitt, J. Bourke, R. A. Greene, C. M. Everard, A. Murphy, and J. E. Lutomski, "At what price? A cost-effectiveness analysis comparing trial of labour after previous caesarean versus elective repeat caesarean delivery," PLoS One, vol. 8, no. 3, Article ID e58577, 2013.

[13] K. K. Loo, X. Luo, H. Su, A. Presson, and Y. Li, "Dreams of tigers and flowers: child gender predictions and preference in 
an urban mainland Chinese sample during pregnancy," Women \& Health, vol. 49, no. 1, pp. 50-65, 2009.

[14] M. Boudou, F. Teissèdre, V. Walburg, and H. Chabrol, "Relation entre l'intensité de la douleur de l'accouchement et celle du postpartum blues," L'Encéphale, vol. 33, no. 5, pp. 805-810, 2007.

[15] J. C. Eisenach, P. H. Pan, R. Smiley, P. Lavand'homme, R. Landau, and T. T. Houle, "Severity of acute pain after childbirth, but not type of delivery, predicts persistent pain and postpartum depression," Pain, vol. 140, no. 1, pp. 87-94, 2008.

[16] T. Ding, D. X. Wang, Y. Qu, Q. Chen, and S. N. Zhu, "Epidural labor analgesia is associated with a decreased risk of postpartum depression: a prospective cohort study," Anesthesia and Analgesia, vol. 119, no. 2, pp. 383-392, 2014.

[17] S. Orbach-Zinger, R. Landau, A. B. Harousch et al., "The relationship between women's intention to request a labor epidural analgesia, actually delivering with labor epidural analgesia, and postpartum depression at 6 Weeks: a prospective observational study," Anesthesia \& Analgesia, vol. 126, no. 5, pp. 1590-1597, 2017.

[18] American College of Obstetricians and Gynecologists, "ACOG practice bulletin no. 210 summary," Obstetrics \& Gynecology, vol. 133, no. 3, pp. 837-839, 2019.

[19] S. Vahabi, M. Haidari, S. Akbari Torkamani, and A. Gorbani Vaghei, "New assessment of relationship between Apgar score and early neonatal mortality," Minerva Pediatrica, vol. 62, no. 62, pp. 249-252, 2010.

[20] G. A. Hawker, S. Mian, T. Kendzerska, and M. French, "Measures of adult pain: visual analog scale for pain (VAS pain), numeric rating scale for pain (NRS pain), McGill pain questionnaire (MPQ), short-form McGill pain questionnaire (SF-MPQ), chronic pain grade scale (CPGS), short form-36 bodily pain scale (SF)," Arthritis Care \& Research, vol. 63, no. S11, pp. S240-S252, 2011.

[21] J. L. Cox, J. M. Holden, and R. Sagovsky, "Detection of postnatal depression," British Journal of Psychiatry, vol. 150, no. 6, pp. 782-786, 1987.

[22] K. L. Wisner, B. L. Parry, and C. M. Piontek, "Postpartum depression," New England Journal of Medicine, vol. 347, no. 3, pp. 194-199, 2002.

[23] M. Lin and G. Li, "Clinical analysis of sickness rate and effect factors of postpartum psychosis," China Medical Herald, vol. 32, 2007.

[24] P. Hiltunen, T. Raudaskoski, H. Ebeling, and I. Moilanen, "Does pain relief during delivery decrease the risk of postnatal depression?," Acta Obstetricia et Gynecologica Scandinavica, vol. 83, no. 3, pp. 257-261, 2004.

[25] R. Armony-Sivan, J. Shao, M. Li et al., "No relationship between maternal iron status and postpartum depression in two samples in China," Journal of Pregnancy, vol. 2012, Article ID 521431, 7 pages, 2012.

[26] X.-S. Zhang, G.-L. Zhao, and L.-J. Chen, "Onset, prognosis and effect factors of postpartum depression," Maternal and Child Health Care of China, vol. 2009, no. 22, p. 5, 2009.

[27] L. J. Miller, "Postpartum depression," JAMA, vol. 287, no. 6, pp. $762-765,2002$.

[28] H. Uriel, "Postpartum disorders: multiple interacting underlying mechanisms and risk factors," Journal of Affective Disorders, vol. 88, no. 1, pp. 1-7, 2005.

[29] P. Stourac, "The analgesic efficacy of remifentanil for labour. Systematic review of the recent literature," Biomedical Papers of the Medical Faculty of the University Palacky Olomouc Czechoslovakia, vol. 160, no. 1, pp. 30-38, 2015.
[30] A. Gari, A. Aziz, N. ALSaleh, Y. Hamour, H. Abdelal, and R. Sayed Ahmed, "Awareness of epidural analgesia among pregnant women in Jeddah, Saudi Arabia," Electronic Physician, vol. 9, no. 5, pp. 4274-4280, 2017.

[31] B. G. M. De, "Analysis of resident anesthesiologists' difficulties with epidural analgesia for labor and childbirth and complication rates," Revista Espaola De Anestesiología Y Reanimación, vol. 54, no. 2, pp. 78-85, 2007.

[32] B. Carvalho, A. J. Fuller, C. Brummel, M. Durbin, and E. T. Riley, "Fetal oxygen saturation after combined spinalepidural labor analgesia: a case series," Journal of Clinical Anesthesia, vol. 19, no. 6, pp. 476-478, 2007.

[33] I. A. Strigo, A. N. Simmons, S. C. Matthews, A. D. Craig, and M. P. Paulus, "Association of major depressive disorder with altered functional brain response during anticipation and processing of heat pain," Archives of General Psychiatry, vol. 65 , no. 11, p. 1275, 2008.

[34] T. Pearlstein, M. Howard, A. Salisbury, and C. Zlotnick, "Postpartum depression," American Journal of Obstetrics and Gynecology, vol. 200, no. 4, pp. 357-364, 2009.

[35] T. Field, "Postpartum depression effects on early interactions, parenting, and safety practices: a review," Infant Behavior and Development, vol. 33, no. 1, pp. 1-6, 2010.

[36] L. S. P. de Almeida, K. Jansen, C. A. Köhler et al., "Working and short-term memories are impaired in postpartum depression," Journal of Affective Disorders, vol. 136, no. 3, pp. 1238-1242, 2012.

[37] C. Reck, A. Hunt, T. Fuchs et al., "Interactive regulation of affect in postpartum depressed mothers and their infants: an overview," Psychopathology, vol. 37, no. 6, pp. 272-280, 2004.

[38] J. Leiferman, "The effect of maternal depressive symptomatology on maternal behaviors associated with child health," Health Education \& Behavior, vol. 29, no. 5, pp. 596-607, 2002.

[39] S. M. Marcus, "Depression during pregnancy: rates, risks and consequences-Motherisk update 2008," The Canadian Journal of Clinical Pharmacology, vol. 16, no. 1, p. e15, 2009.

[40] E. Robertson, S. Grace, T. Wallington, and D. E. Stewart, "Antenatal risk factors for postpartum depression: a synthesis of recent literature," General Hospital Psychiatry, vol. 26, no. 4, pp. 289-295, 2004.

[41] K. S. Kendler, C. O. Gardner, and C. A. Prescott, "Toward a comprehensive developmental model for major depression in women," American Journal of Psychiatry, vol. 159, no. 7, pp. 1133-1145, 2002.

[42] J. W. Liu, "Evaluation for the status of anxiety and depression in liver-transplant patients," Chinese Journal of Clinical Rehabilitation, vol. 10, no. 38, pp. 17-19, 2006.

[43] J. Li, X. Wu, J. Lin et al., "Type D personality, illness perception, social support and quality of life in continuous ambulatory peritoneal dialysis patients," Psychology, Health \& Medicine, vol. 22, no. 2, pp. 196-204, 2017.

[44] S. J. Iyer and S. Leo, "Maintenance of neuraxial block in labor analgesia," Trends in Anaesthesia \& Critical Care, vol. 2, no. 4, pp. 199-204, 2012.

[45] R. Jouppila, "The effect of segmental epidural analgesia on maternal prolactin during labour," British Journal of $\mathrm{Ob}$ stetrics and Gynaecology, vol. 87, no. 3, pp. 234-238, 2010.

[46] A. L. Bianchi and E. D. Adams, "Labor support during second stage labor for women with epidurals," Nursing for Womens Health, vol. 13, no. 1, pp. 38-47, 2010.

[47] DSM-IV-T R, Diagnostic and Statistical Manual of Mental Disorders, American Psychiatric Association, Philadelphia, PA, USA, 2000. 
[48] D. T. S. Lee, A. S. K. Yip, S. S. M. Chan, M. H. Y. Tsui, W. S. Wong, and T. K. H. Chung, "Postdelivery screening for postpartum depression," Psychosomatic Medicine, vol. 65, no. 3, pp. 357-361, 2003.

[49] D. T. S. Lee, A. S. K. Yip, H. F. K. Chiu, T. Y. S. Leung, and T. K. H. Chung, "Screening for postnatal depression: are specific instruments mandatory?," Journal of Affective Disorders, vol. 63, no. 1-3, pp. 233-238, 2001.

[50] C. T. Beck and R. K. Gable, "Comparative analysis of the performance of the postpartum depression screening scale with two other depression instruments," Nursing Research, vol. 50, no. 4, pp. 242-250, 2001.

[51] D. T. S. Lee, S. K. Yip, H. F. K. Chiu et al., "Detecting postnatal depression in Chinese women," British Journal of Psychiatry, vol. 172, no. 5, pp. 433-437, 1998.

[52] R.-h. Xie, G. He, A. Liu, J. Bradwejn, M. Walker, and S. W. Wen, "Fetal gender and postpartum depression in a cohort of Chinese women," Social Science \& Medicine, vol. 65, no. 4, pp. 680-684, 2007. 


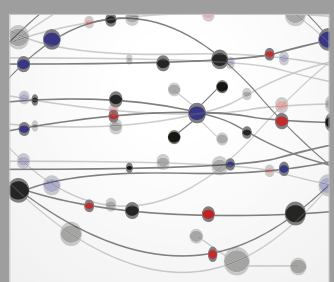

The Scientific World Journal
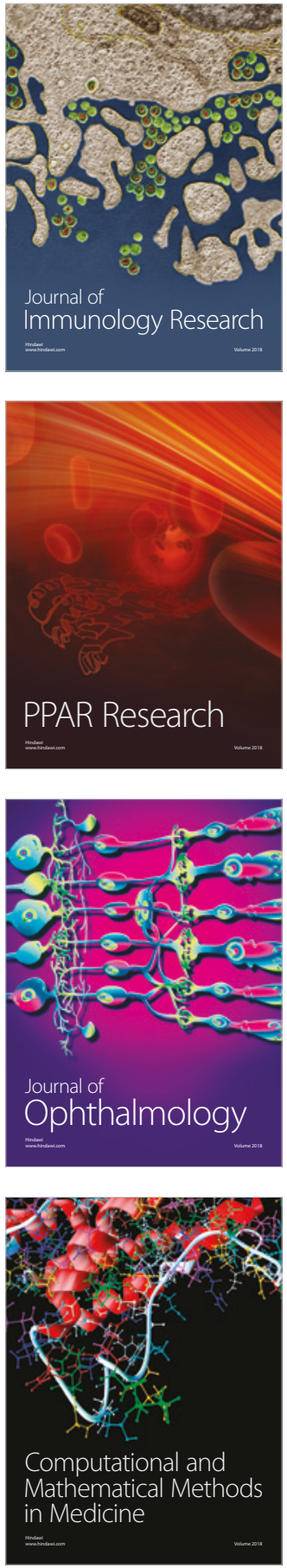

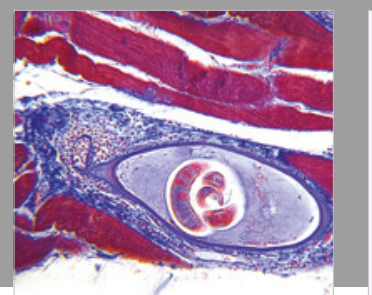

Gastroenterology Research and Practice

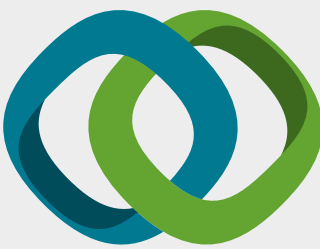

\section{Hindawi}

Submit your manuscripts at

www.hindawi.com
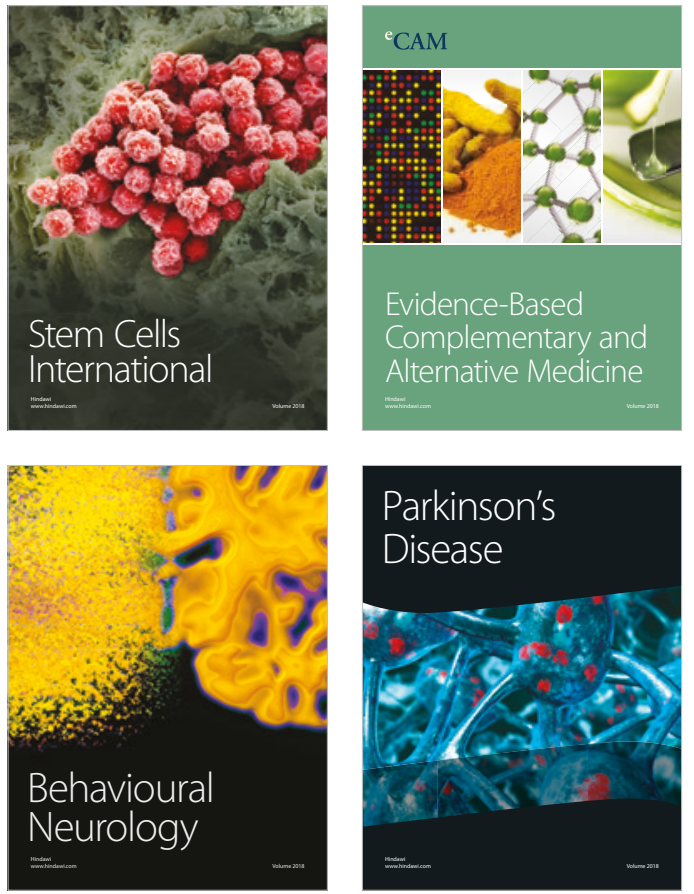

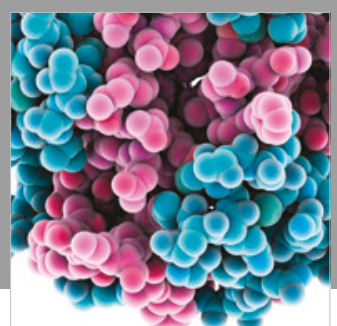

ournal of

Diabetes Research

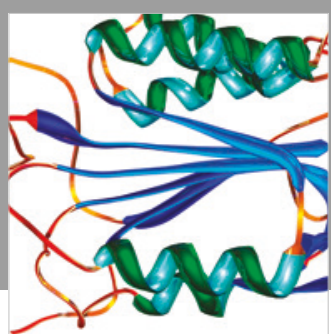

Disease Markers
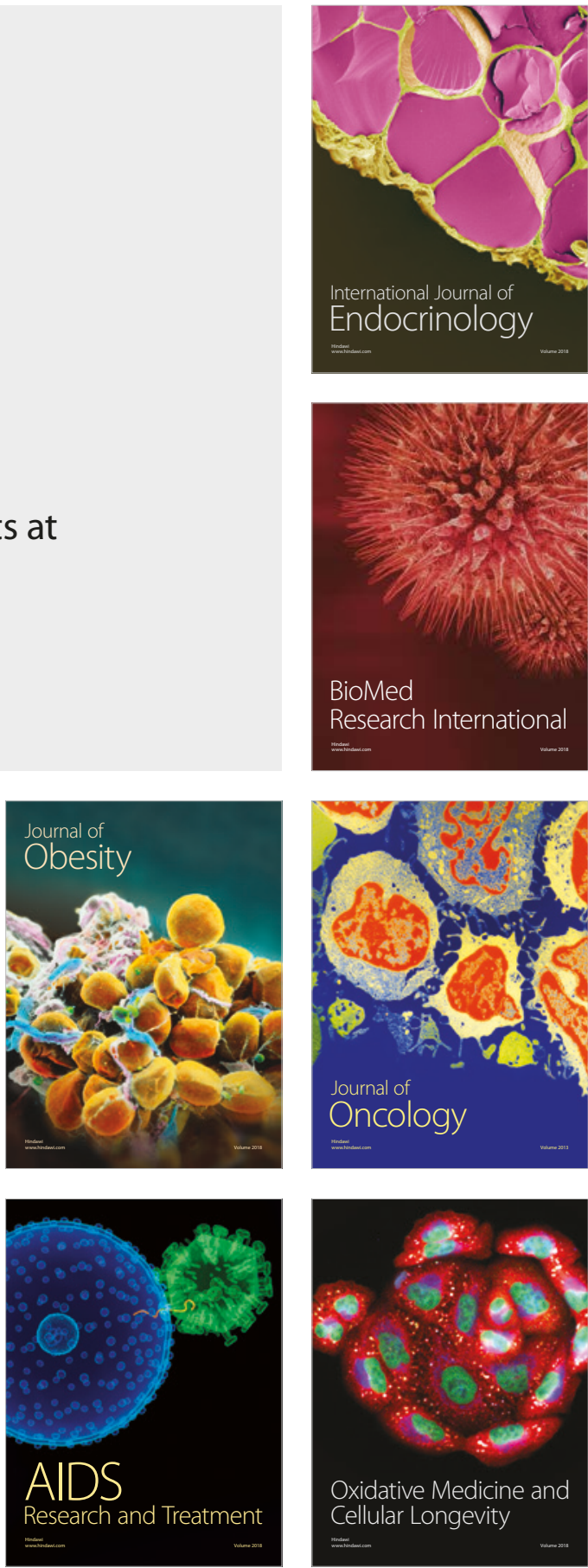